\title{
Time and Resources Needed to Document Patients with Breast Cancer from Primary Diagnosis to Follow-up - Results of a Single-center Study
}

\author{
Dokumentationsaufwand einer Patientin mit einem Mammakarzinom von Primärdiagnose bis Follow-up \\ und verbundenen Ressourcen - Ergebnisse der unizentrischen Phase
}

Authors

Affiliations
M. P. Lux ${ }^{1 *}$, C. S. Sell ${ }^{1 *}$, P. A. Fasching ${ }^{1}$, J. Seidl-Ertel ${ }^{1}$, M. R. Bani ${ }^{1}$, M. G. Schrauder ${ }^{1}$, S. M. Jud ${ }^{1}$, C. R. Loehberg ${ }^{1}$, C. Rauh ${ }^{1}$, A. Hartmann ${ }^{2}$, R. Schulz-Wendtland ${ }^{3}$, V. Strnad ${ }^{4}$, M. W. Beckmann ${ }^{1}$

${ }^{1}$ Frauenklinik, Universitätsklinikum Erlangen, CCC ER-EMN, Universitäts-Brustzentrum Franken, Erlangen

2 Pathologisches Institut der Universität Erlangen, CCC ER-EMN, Universitäts-Brustzentrum Franken, Erlangen

3 Radiologisches Institut, Universitätsklinikum Erlangen, CCC ER-EMN, Universitäts-Brustzentrum Franken, Erlangen

${ }^{4}$ Strahlenklinik, Universitätsklinikum Erlangen, CCC ER-EMN, Universitäts-Brustzentrum Franken, Erlangen
Key words

- breast cancer

- resources

- documentation

- quality assurance

- personnel costs

Schlüsselwörter

- Mammakarzinom

- Ressourcen

- Dokumentation

- Qualitätssicherung

- Personalaufwand

Deutschsprachige Zusatzinformationen online abrufbar unter: www.thieme-connect.de/ ejournals/toc/gebfra

$\begin{array}{lr}\text { received } & 23.5 .2014 \\ \text { revised } & 15.7 .2014 \\ \text { accepted } & 16.7 .2014\end{array}$

Bibliography

DOI http://dx.doi.org/

10.1055/s-0034-1382980

Geburtsh Frauenheilk 2014; 74 :

743-751 @ Georg Thieme

Verlag KG Stuttgart · New York . ISSN 0016-5751

\section{Correspondence}

Prof. Dr.

Matthias W. Beckmann

Frauenklinik

Universitätsklinik Erlangen

Universitätsstraße 21-23

91054 Erlangen

fk-direktion@uk-erlangen.de

\section{Abstract \\ $\nabla$}

Aim: Certification of breast centers helps improve the quality of care but requires additional resources, particularly for documentation. There are currently no published data on the actual staff costs and financial resources required for such documentation. The aim of this study was to determine the time and resources required to document a patient with primary breast cancer from diagnosis to the end of follow-up, to establish a database for future strategic decisions.

Material and Methods: All diagnostic and therapeutic procedures of patients with primary breast cancer were recorded at the University Breast Center of Franconia. All time points for documentation were evaluated using structured interviews. The times required to document a representative number of patients were determined and combined with the staff costs of the different professional groups, to calculate the financial resources required for documentation.

Results: A total of 494 time points for documentation were identified. The study also identified 21 departments and 20 different professional groups involved in the documentation. The majority (54\%) of documentation was done by physicians. $62 \%$ of all documentation involved outpatients. The results of different scenarios for the diagnosis, therapy and follow-up of breast cancer patients in a certified breast center showed that the time required for documentation can be as much as 105 hours, costing $€ 4135$.

Conclusion: This analysis shows the substantial staffing and financial costs required for documentation in certified centers. A multi-center study will be carried out to compare the costs for certified breast centers of varying sizes with the costs of non-certified care facilities.

\section{Zusammenfassung \\ $\nabla$}

Zielsetzung: Zentrumsbildung mit Zertifizierung hat einen qualitätsoptimierenden Effekt, fordert jedoch zusätzliche Ressourcen, insbesondere für die Dokumentation. Da bisher keine publizierten Daten zum tatsächlichen Dokumentationsaufwand vorliegen, wurde dieser im vorliegenden Projekt für Patientinnen mit einem primären Mammakarzinom ermittelt, um eine Datenlage für zukünftige strategische Entscheidungen zu etablieren.

Material und Methoden: Im Rahmen des unizentrischen Projekts wurden sämtliche Dokumentationszeitpunkte der gesamten Versorgungskette erfasst. Folgend wurden die Dokumentationszeiten einer repräsentativen Anzahl von Patientinnen ermittelt und der Personalaufwand mit berufsgruppenspezifischen Kosten hinterlegt, um die finanziellen Dokumentationsressourcen darzustellen.

Ergebnisse: Insgesamt wurden 494 Dokumentationszeitpunkte sowie 21 an der Dokumentation beteiligte Fachbereiche und 20 Berufsgruppen ermittelt. Mit 54\% entfällt der größte Dokumentationsanteil auf die ärztliche Berufsgruppe. $62 \%$ aller Dokumentationszeitpunkte betreffen den ambulanten Sektor. In Fallbeispielen einer Mammakarzinompatientin mit Diagnose, Therapie und Nachsorge im zertifizierten Brustzentrum zeigte sich ein Dokumentationsaufwand von bis zu 105 Stunden mit entsprechenden Personalkosten von bis zu $4135 €$.

Zusammenfassung: Die vorliegende Analyse verdeutlicht den erheblichen personellen und finanziellen Aufwand für die Dokumentation in zertifizierten Strukturen. Dies wird folgend in einer multizentrischen Erhebung validiert. 


\section{Introduction}

$\nabla$

According to information from the Federal Statistical Office of Germany, breast cancer is the most common cause of death from malignant disease in women in Germany. According to figures of the Robert Koch Institute for 2010, 70340 women develop breast cancer every year in Germany. The projection for 2014 is 75200 new cases for that year [1]. Allowing for an annual mortality of 17466 women and taking the 10-year follow-up into account, more than half a million women in Germany are currently receiving care and being followed up. An estimated 60000 women additionally have metastases. To put this into context, approximately 32033000 adult women were living in Germany in 2010 [2], meaning that one in 55 women is receiving oncological care or follow-up for breast cancer. These figures show that documentation and quality assurance for breast cancer patients are extremely relevant for healthcare policies and health economics. Documentation and quality assurance are increasingly central for health economics, both nationally and internationally, and it is important that further studies on these topics are carried out [3]. German healthcare policies have also recognized the importance of obtaining more detailed information and have begun to focus more on this aspect. On June 16, 2008, the German Federal Ministry of Health (BMG) launched the National Cancer Plan [4, 5]. The goal of the National Cancer Plan is to optimize the care of cancer patients [6]. Key aspects include improving the provision of oncology services, ensuring guideline-based care and improving quality assurance while ensuring that documentation is both effective and cost-efficient. Cancer is a highly complex disease and it is indisputable that documentation plays an important role during the course of disease and treatment [7]. Moreover, more than for any other disease, cancer treatment involves numerous medical specialties and professional groups from many different care services, and the complexity of the disease means that patients may have to be followed up for the rest of their lives. A reliable and neutral representation of important stations during the course of disease, starting from diagnosis and including treatment and follow-up, is therefore indispensable to optimize care [7]. Tumor documentation is not only necessary when formulating the complex treatment process. In addition to healthcare providers and patients, healthcare insurance companies, researchers and politicians also depend on tumor documentation as a source of reliable information on the quality of oncological care in Germany. However, there are currently a number of problems associated with the quality indicators used to document care for quality assurance purposes. Numerous quality indicators are used to describe the quality of structures, processes and outcomes. But the same indicators are defined differently in different documentation systems. At present, comparisons using different documentation systems are usually not possible (for example, the number of patients with primary breast cancer in a single center: some systems count individual patients, others list each breast separately). There are also many different quality assurance systems in use. Examples for this include the documentation required by the German Cancer Society (DKG) and the German Society for Senology (DGS) from certified breast centers, the data collected by the AQUA Institute, the data required to participate in the Disease Management Program (DMP) Breast Cancer, the data collected for quality assurance purposes in breast cancer screening, etc. The existing documentation systems have very different objectives and describe different aspects of care provi- sion, and data are processed using different systems for data acquisition and reporting.

Certified breast centers provide tertiary care to breast cancer patients and stand in particular need of additional personnel and financial resources to comply with the requirements to document quality parameters.

The tumor documentation of breast cancer patients is thus a prime example of how developments can go wrong. Quality assurance in oncology is currently very heterogeneous in Germany, and clear and uniform guidelines are lacking. Multiple data collections, different documentation systems and partial data collection should be unacceptable; data documentation should always be defined in terms of the goal of the data collection, for example, to certify the quality of services, reinforce compliance with guidelines, improve the process quality and - the most important aspect for patients - improve outcomes. Changes in documentation could reduce the number of staff required and save costs.

But in order to achieve these goals it is necessary to take stock and review the situation as it currently stands, including:

- At which points in the patient's course (from the initial diagnosis to treatment, follow-up and quality assurance) are data generally collected?

- Which parameters are documented?

- Who (professional group/medical specialty) does the documenting?

- Which financial resources are currently required for a complete documentation of a breast cancer patient?

To calculate the resources actually needed for documentation, identify which data is collected unnecessarily several times over, and establish where interfaces exist which could be used to optimize data collection across all areas, it is necessary to capture and describe the current status of data collection. The obvious gap between currently available resources for data collection and what would actually be needed has not been previously investigated. This is surprising, considering the costs and time spent on documentation. The aim of this study was to provide a detailed horizontal cross-section of the time, costs and staff involved in documenting a patient with primary breast cancer from initial diagnosis and including treatment, follow-up and quality assurance, and to determine the different time points for data collection and the collected parameters.

\section{Material and Methods}

$\nabla$

Location of the study

The single-center study was carried out in the University Breast Center Franconia (UBF) in the Gynecological Department of the University Hospital of Erlangen and the Comprehensive Cancer Center Erlangen-EMN in cooperation with outpatient facilities in the region. The UBF has been certified since 2004 by TÜV-Süd Management Service GmbH and since 2005 by the European Society of Mastology (EUSOMA); certification was in accordance with the criteria of the DKG and the DGS and DIN EN ISO 9001:2008. The Center was chosen for the study because it is both a university hospital and a tertiary care center for the region Erlangen-Fürth-Nuremberg and offers care to patients from all three major cities. In 2011, the year this survey was carried out, 7645 patients received care and treatment, 4808 of them in hospital and 1134 of them in the form of surgical procedures performed on an outpatient basis. A total of 465 women presented 
with primary breast cancer. The Breast Center also houses the assessment center for mammography screening for Middle Franconia. This makes the UBF a good choice of location for a study aiming to identify the costs, time and staff involved in documenting breast cancer patients.

In addition to the various partners cooperating with the University Breast Center Franconia, all participating care services, including in-patient and out-patient facilities, were also integrated in the study; these included gynecologists in private practice, GPs, specialists in internal medicine, dentists, the mammography screening program for Middle Franconia, the Tumor Center Erlangen-Nuremberg and the Human Genetics Department of the University of Würzburg.

\section{Individual stages}

The single-center study was carried out in several different stages. To begin with, every detail of the "chain of care" offered to breast cancer patients had to be determined in order to subsequently pinpoint at which points data are collected along the chain and who does the collecting. Data collection starts at the point when the diagnosis is made and includes investigations by specialist doctors or presentation to the Center or a diagnosis obtained as part of the statutory mammography screening program; this is followed by treatment planning which can include primary surgery and secondary systemic therapy or primary systemic therapy with secondary surgery as well as psycho-oncological care, human genetics, follow-up and quality assurance. All drug-based therapies (e.g. endocrine therapy, chemotherapy, targeted therapies, bisphosphonates) and radiotherapies (conventional, brachytherapy) and the additional diagnostics required for these therapies, the care required to deal with side-effects, any participations in trials and incidence of recurrence were also looked at. Another key area consisted of determining the additional documentation required for quality assurance and quality management including certification, which is done for a period of 10 years after primary diagnosis.

The respective time points for data collection and documentation were determined. The next step was a feasibility study which reviewed the data collection instruments to determine the time and costs involved in documentation. A number of modifications were carried out to optimize data collection. The concept which had been developed was then tested, and the time and costs involved in documentation were calculated in terms of a proof of concept.

The single-center study was expanded - with the support of German Federal Ministry of Health (BMG) - and the number of cases was increased and a more differentiated examination of different, potentially complex processes was carried out. This made it possible to simulate every potential course a patient could take together with the costs and staff involved in each documentation process.

\section{Data collection}

Because of the wide range of professions, medical specialties, sectors and systems as well as the fact that some of the documentation was handwritten, it was not possible to do a targeted data retrieval of the above-listed parameters using documentation programs. Data was collected at the data entry points and the respective time required for documentation was timed $(n=166$, $33.6 \%$ ). If this was not possible, for example, in systematic evaluations done for quality assurance, the time required was recorded based on structured interviews $(n=251,50.8 \%)$. At the request of some of the professional groups involved, this data was also collected using structured questionnaires ( $n=77,15.6 \%$ ).

In addition to determining the time required for data collection, the following parameters were also investigated for every point of documentation: time point of the documentation, situation (diagnosis, therapy, follow-up, other), sector (outpatient, in-patient), reason for data collection at this point (organization, talk, diagnosis, therapy, data collection for a trial, quality assurance, other), the medical specialty and professional group doing the documentation, the times between data collections (once-off, several times including frequency and total number of times, and whether this was the first contact with the patient or a repeat meeting, e.g. during ongoing systemic therapy), and what sort of data was recorded.

\section{Patient cohort}

All patients with standard disease which corresponded to the standard chain of care were included in the study. Patients with metastasis were excluded. A representative number of patients was assessed at each point of documentation $(n=5-10$ patients per variable). A cross-sectional survey was done.

\section{Evaluation}

Data collection, data administration and data evaluation for the expanded single-center study was done using the SPSS 16.0 program. Access to data was limited to the members of the study. The collected variables were managed in modules, allowing the targeted retrieval of all potential patient courses.

Costs of documentation were calculated using the data obtained for documentation times which was linked to the professional group involved in the documentation and the costs for this group. The standard pay scales for university hospitals applicable in 2011 (i.e., at the time of the study) were used to calculate the personnel costs for the employees of Erlangen University Hospital. The full costs for each member of staff were used, based on the salary scales for employees in the respective professional groups. Costs for physicians were calculated using the Labor and Salary Agreement for Physicians Working in University Hospitals (TVÄrzte) of October 30, 2006 in the version of the Modified Collective Labor Agreement No. 1 of August 17, 2009 [8]. The salaries and wages of external professional groups were calculated, based on the relevant collective labor agreements applicable at the time of collecting data for the study [9] ( $\odot$ Table $\mathbf{1}$ ).

\section{Results}

\section{$\nabla$}

\section{Distribution of documentation times}

Data were collected at 494 specific time points, although documentations were sometimes done repeatedly (e.g., a systemic therapy with 6 cycles of therapy involves repeating the documentation six times). $71.5 \%$ of all documentations related to direct therapy, $13.7 \%$ were for diagnosis and planning of therapy, and $14.4 \%$ were for subsequent follow-up and quality assurance. - Table 2 shows the distribution of documentation times according to categories and the respective percentage of documentation time required for each category. Therapy requires the largest share of time used for documentation. The different variables are distributed across various therapy modules and depend on the specific needs of the individual patient. Adjuvant and neoadjuvant chemotherapy and primary or secondary surgery account for a large number of the documentations. 
Table 1 Full costs for a member of staff per hour for each professional group.

\begin{tabular}{|lc|}
\hline Professional group & $\begin{array}{l}\text { Full cost of a } \\
\text { member of staff } \\
\text { per hour (in } € \text { ) }\end{array}$ \\
& 35.15 \\
\hline Resident physician, physician/SHI, lab consultant & 52.65 \\
\hline Senior physician & 49.71 \\
\hline $\begin{array}{l}\text { Pharmacist, computer scientist, physicist, } \\
\text { social support services, psycho-oncology }\end{array}$ & 40.07 \\
\hline Documentation staff, physiotherapy/hospital & 33.09 \\
\hline Nurses, medical typist, secretary, hygiene specialist & 30.12 \\
\hline Medical assistant/hospital, study nurse & 37.23 \\
\hline Assistant radiographer/hospital, & \\
\hline pharmacy technician/hospital & 6.80 \\
\hline Student research assistant & 49.09 \\
\hline General medical practitioner & 54.34 \\
\hline Gynecologist/outpatients & 105.49 \\
\hline Radiologist/outpatients & 63.19 \\
\hline Dentist/outpatients & 9.73 \\
\hline Medical assistant, dental assistant/outpatients & 13.67 \\
\hline Physiotherapy/outpatients & 19.28 \\
\hline Assistant radiologist/outpatients &
\end{tabular}

\section{Medical specialties and professional groups}

\section{doing the documentation}

Analysis shows that up to 21 medical specialties are involved in the documentation of a patient with breast cancer across the entire course of disease ( Table 3 ). The majority of documentations are done by gynecologists or gynecological staff.

Up to 20 different professional groups can be involved in documenting a patient with breast cancer ( $\odot$ Table 4). Physicians constitute the largest group involved in documentation (53.7\%). Resident physicians usually do the majority of this documentation.

\section{Documentation in different medical sectors}

Breast cancer patients are documented in a number of different medical sectors. The majority of documentation is done when the patient is an outpatient $(61.94 \%, \mathrm{n}=306)$ as, in addition to diagnosis and follow-up, the lion's share of treatment is done on an outpatient basis. In-patient documentation is done primarily during primary or secondary surgical procedures and at the beginning of systemic therapy $(18.22 \%, \mathrm{n}=90)$. "Other" refers to documentations $(19.84 \%, n=98)$ which cannot be assigned to an outpatient or in-patient setting. Examples include documentation done for quality assurance which is not represented at other documentation stages and documentation for quality management, which is done for in-patients and outpatients alike.

\section{Reasons for documentation}

Documentation is done for a number of different reasons. A single documentation can combine several different reasons ( $\mathrm{Fig.1}$ ). Documentation is generally done for organizational purposes. Very few documentations $(n=58)$ did not have an organizational purpose. 39.3\% $(n=194)$ of documentations were done to document discussions with the patient and other professionals. Around one third of documentations included diagnostic information $(36.0 \%$ [ $n=173])$. Just under half of all documentations were done to document information on therapies $(41.9 \%$ $[n=207]$ ). $58.6 \%$ of documentations recorded information from investigations obtained for purely diagnostic purposes, followup information after completing therapy, information on quality assurance or were undertaken as part of a study.
Table 2 Distribution of documentations according to category.

\begin{tabular}{|c|c|c|}
\hline Subgroups & $\begin{array}{l}\text { Number of } \\
\text { documen- } \\
\text { tations }\end{array}$ & $\begin{array}{l}\text { Per- } \\
\text { cent }\end{array}$ \\
\hline $\begin{array}{l}\text { Primary diagnosis obtained from a } \\
\text { gynecological practice (histology and } \\
\text { diagnosis from a radiological practice) }\end{array}$ & 12 & 2.4 \\
\hline $\begin{array}{l}\text { Primary diagnosis from a gynecological } \\
\text { practice (without histology) }\end{array}$ & 8 & 1.6 \\
\hline $\begin{array}{l}\text { Primary diagnosis from a mammography } \\
\text { screening program with assessment } \\
\text { (including histology) }\end{array}$ & 29 & 5.9 \\
\hline $\begin{array}{l}\text { Primary diagnosis from a breast center } \\
\text { (including histology) }\end{array}$ & 13 & 2.6 \\
\hline Primary therapy in a breast center & 11 & 2.2 \\
\hline Primary neoadjuvant therapy & 45 & 9.1 \\
\hline Primary antibody therapy & 13 & 2.6 \\
\hline Secondary operation after neoadjuvant therapy & 57 & 11.5 \\
\hline Postoperative planning after secondary surgery & 7 & 1.4 \\
\hline Primary surgery & 67 & 13.6 \\
\hline Postoperative planning after primary surgery & 8 & 1.6 \\
\hline Primary postoperative adjuvant chemotherapy & 29 & 5.9 \\
\hline Chemotherapy per cycle & 60 & 12.1 \\
\hline Primary adjuvant antibody therapy & 26 & 5.3 \\
\hline Primary adjuvant bisphosphonate therapy & 21 & 4.3 \\
\hline Radiotherapy & 18 & 3.6 \\
\hline Follow-up gynecology/radiology/radiotherapy & 24 & 4.9 \\
\hline Outpatient follow-up & 5 & 1.0 \\
\hline Psycho-oncology & 7 & 1.4 \\
\hline Human genetics & 8 & 1.6 \\
\hline Databases/quality assurance & 17 & 3.4 \\
\hline Quality management & 9 & 1.8 \\
\hline Total & 494 & 100.0 \\
\hline
\end{tabular}

Quality assurance and quality management

Almost half of all documentation ( $46.8 \%$ [ $n=231]$ ) is for quality assurance (documentation to improve process quality and outcomes). This is necessary because quality assurance requires detailed and comprehensive information. Data collection is done to obtain data for clinical and epidemiological cancer registers, for the Disease Management Program Breast Cancer and for the AQUA institutes. In the interests of patient safety and for quality assurance purposes, a hygiene specialist regularly collects data on compliance with official hygiene guidelines. Data is also collected and evaluated in certified breast centers in accordance with the criteria of the German Cancer Society (DKG) and the German Society for Senology (DGS). And data is also collected during mammography screening for quality assurance purposes. As part of quality management, data is regularly collected to determine levels of patient satisfaction, waiting times, etc., as part of the requirements for DIN ISO certification and in accordance with the criteria of the DKG and DGS. In addition to patient satisfaction, the satisfaction of physicians working in private practice is also documented.

\section{Documentation of standard case histories}

Based on the collected data, it was possible to determine the time and cost of documentation for different courses of disease in breast cancer patients. A number of standard courses of disease are discussed here to show the resources required for these patients and demonstrate the diversity in terms of the time and cost needed for documentation. 


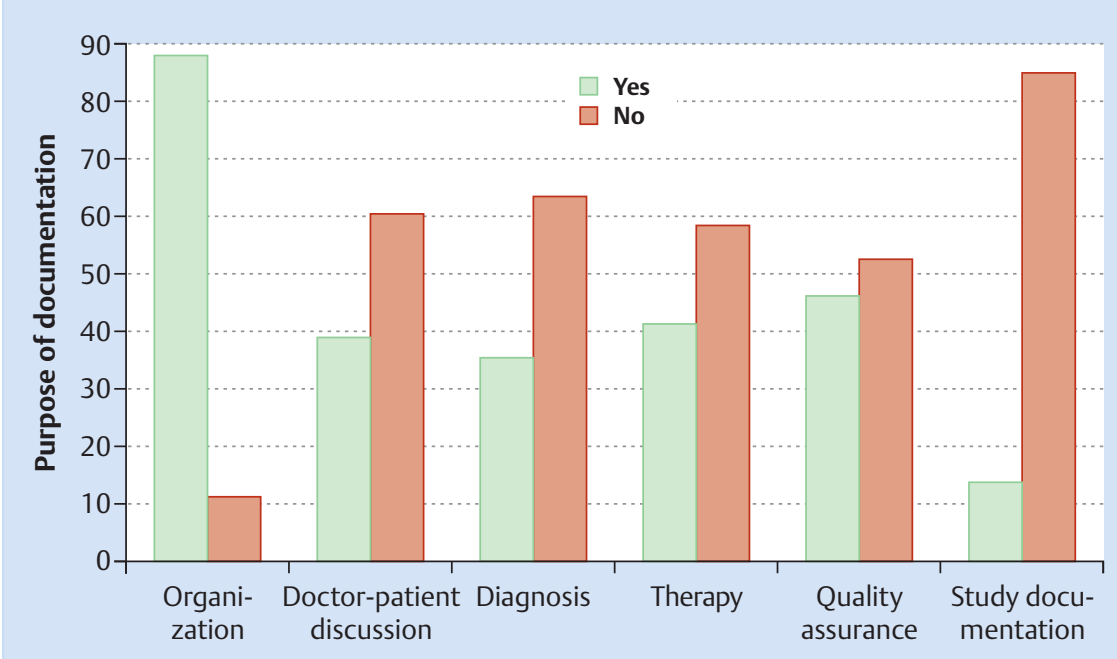

Fig. 1 Reasons for different documentations.

The first example shows the time and cost of documentation for a 51-year-old patient with a familial history positive for breast cancer. After the initial diagnosis obtained from a gynecological practice is suspicious for breast cancer, findings are confirmed in a certified breast center. For HER2-positive and hormone receptor-positive breast cancer, an interdisciplinary tumor conference recommends staging followed by neoadjuvant chemotherapy plus trastuzumab. After completing neoadjuvant systemic therapy, the patient will undergo breast-conserving surgery. This is followed by radiotherapy, another round of therapy with trastuzumab and endocrine therapy. In addition, the patient will receive psycho-oncological support throughout her therapy. If there is a positive familial history of breast cancer, genetic counselling and testing will be done. The total time required to document a pa- tient with this case history, from the time of initial diagnosis to the end of 10 years' follow-up including quality assurance, was 105 hours and 39 minutes ( Table 5). After linking the respective documentation to the professional group who did the documentation and based on the staff costs for the respective professional group, the cost of documentation across the entire period was $€ 4134.92$.

The 2nd case history is for a patient with a ductal carcinoma in situ (DCIS); diagnosis and confirmation is done at mammography screening; primary therapy is done in a certified breast center and includes breast-conserving therapy with subsequent radiotherapy, psycho-oncological care, and standard follow-up. The total time required for documentation is 55 hours and 34 minutes at a total cost of $€ 2124.87$ ( Table 6).
Table 3 Distribution of documentations across the different medical specialties.

\begin{tabular}{|c|c|c|}
\hline Medical specialty & $\begin{array}{l}\text { Number of } \\
\text { documentations }\end{array}$ & Percent \\
\hline General medicine & 8 & 1.6 \\
\hline Anesthesia & 18 & 3.6 \\
\hline Pharmacology & 28 & 5.7 \\
\hline Documentation in the Tumor Center & 9 & 1.8 \\
\hline Vascular Surgery & 4 & 0.8 \\
\hline Gynecology & 195 & 39.5 \\
\hline Human genetics & 7 & 1.4 \\
\hline Cardiology & 14 & 2.8 \\
\hline $\begin{array}{l}\text { Association of Statutory Health } \\
\text { Insurance Physicians in Bavaria }\end{array}$ & 1 & 0.2 \\
\hline Laboratory medicine & 6 & 1.2 \\
\hline Nuclear medicine & 16 & 3.2 \\
\hline Orthopedics & 2 & 0.4 \\
\hline Pathology & 27 & 5.5 \\
\hline Physiotherapy & 3 & 0.6 \\
\hline Psycho-oncology & 6 & 1.2 \\
\hline Radiology & 60 & 12.1 \\
\hline Social services & 2 & 0.4 \\
\hline Radiotherapy & 17 & 3.4 \\
\hline Study management & 46 & 9.3 \\
\hline Administration & 19 & 3.8 \\
\hline Dentistry & 6 & 1.2 \\
\hline Total & 494 & 100.0 \\
\hline
\end{tabular}

Table 4 Distribution of documentations across the different professional groups.

\begin{tabular}{lcr} 
Professional group & $\begin{array}{c}\text { Number of } \\
\text { documentations }\end{array}$ & Percent \\
Physician SHI & 1 & 0.2 \\
\hline Medical assistant & 33 & 6.7 \\
\hline Resident physician & 192 & 38.9 \\
\hline Documentation staff & 21 & 4.3 \\
\hline Specialist consultant & 33 & 6.7 \\
\hline Hygiene specialist & 2 & 0.4 \\
\hline Computer scientist & 2 & 0.4 \\
\hline Senior physician & 39 & 7.9 \\
\hline Nursing staff & 54 & 10.9 \\
\hline Pharmacist & 20 & 4.0 \\
\hline Pharmacist's assistant & 8 & 1.6 \\
\hline Physicist & 1 & 0.2 \\
\hline Physiotherapist & 3 & 0.6 \\
\hline Psycho-oncologist & 6 & 1.2 \\
\hline Radiology assistant & 24 & 4.9 \\
\hline Medical typist & 17 & 3.4 \\
\hline Secretary & 7 & 1.4 \\
\hline Social service worker & 2 & 0.4 \\
\hline Student & 5 & 1.0 \\
\hline Study nurse & 24 & 4.9 \\
\hline Total & 494 & 100.0 \\
\hline
\end{tabular}


Table 5 Time and cost of documentation for case history l.

\begin{tabular}{|lrr|}
\hline Documentation & $\begin{array}{c}\text { Total time } \\
\text { (h:m:s) }\end{array}$ & \multicolumn{1}{c|}{$\begin{array}{c}\text { Total cost } \\
\text { (in } € \text { ) }\end{array}$} \\
$\begin{array}{l}\text { Primary diagnosis } \\
\text { in a gynecological practice }\end{array}$ & 13.91 \\
\hline $\begin{array}{l}\text { Primary diagnosis and therapy } \\
\text { in a breast center }\end{array}$ & $1: 05: 52$ & 42.82 \\
\hline Primary neoadjuvant chemotherapy & $25: 38: 33$ & 1009.67 \\
\hline Secondary operation & $6: 25: 58$ & 238.88 \\
\hline Postoperative planning & $0: 14: 01$ & 10.95 \\
\hline Adjuvant antibody therapy & $14: 50: 44$ & 611.96 \\
\hline Adjuvant bisphosphonate therapy & $6: 30: 50$ & 315.27 \\
\hline Radiotherapy & $28: 20: 00$ & 1057.76 \\
\hline Follow-up (follow-up/radiotherapy) & $12: 57: 00$ & 501.03 \\
\hline Psycho-oncology & $1: 31: 20$ & 73.20 \\
\hline Human genetics & $3: 38: 00$ & 145.91 \\
\hline Quality assurance & $3: 19: 41$ & 72.84 \\
\hline Quality management & $0: 50: 50$ & 40.72 \\
\hline Total & $\mathbf{1 0 5 : 3 9 : 4 9}$ & $\mathbf{4 1 3 4 . 9 2}$ \\
\hline
\end{tabular}

The 3rd case history is for a patient with breast cancer who receives her primary diagnosis from a gynecological practice; subsequent primary diagnosis and therapy is done by a certified breast center and includes gynecological radiology and histology, primary breast-conserving surgery and adjuvant chemotherapy as part of a clinical trial, psycho-oncological care, radiotherapy and standard follow-up ( Table 7).

The 4th case history is a standard disease course for an elderly patient (primary diagnosis in a gynecological practice with mammography and punch biopsy, further diagnosis and therapy in a certified breast center including gynecological radiology [ultrasound diagnostics], primary surgery with mastectomy, endocrine therapy and standard follow-up). Total time required for documentation is 17 hours and 49 minutes at a total cost of $€ 660.46$ from diagnosis to the end of follow-up ( $\bullet$ Table 8).

\section{Multiple documentations/}

\section{frequency of documented content}

Multiple documentations are made at certain times of data collection. In general, several contents are documented during a single documentation session (e.g., name, date of birth, tumor stage, etc.). As part of the expanded single-center study carried out at
Table 6 Time and cost of documentation for case history II.

\begin{tabular}{|lrr|}
\hline Documentation & $\begin{array}{c}\text { Total time } \\
\text { (h:m:s) }\end{array}$ & \multicolumn{1}{c|}{$\begin{array}{c}\text { Total cost } \\
\text { (in } € \text { ) }\end{array}$} \\
\begin{tabular}{|lr} 
Primary diagnosis \\
during mammography screening
\end{tabular} & 112.06 \\
\hline $\begin{array}{l}\text { Primary diagnosis and therapy } \\
\text { in a breast center }\end{array}$ & $0: 08: 24$ & 6.40 \\
\hline Primary surgery & $6: 48: 18$ & 253.93 \\
\hline Postoperative planning & $0: 08: 14$ & 5.87 \\
\hline Radiotherapy & $28: 20: 00$ & 1057.76 \\
\hline Follow-up (follow-up/radiotherapy) & $12: 57: 00$ & 501.03 \\
\hline Psycho-oncology & $1: 31: 20$ & 73.20 \\
\hline Quality assurance & $3: 21: 36$ & 73.90 \\
\hline Quality management & $0: 50: 50$ & 40.72 \\
\hline Total & $\mathbf{5 5 : 3 4 : 4 6}$ & $\mathbf{2 1 2 4 . 8 7}$ \\
\hline
\end{tabular}

the University Breast Center Franconia, it was specified which parameters would be documented at every single documentation time point. Database queries can then be used to show how often every parameter (e.g. tumor stage) is documented and which professional group or medical specialty did the documenting. This creates transparency and illustrates when multiple documentations are done with overlapping information. It is important to note that certain documentation time points may recur several times (e.g., during chemotherapy with $4 \times$ EC and $12 \times$ paclitaxel there will be 16 repetitions), so that the true extent of multiple documentation is significantly higher. It should also be noted, however, that certain contents are generated automatically (e.g. in the form of patient stickers containing data which are used repeatedly at different documentation time points) or are automatically printed out by digital systems. Moreover, certain contents are only documented if they are abnormal. A total of 234 different contents can be documented. 37 contents are recorded at more than $50 \%$ of documentation times. 21 contents are recorded between $>40$ and $50 \%$ of time points, 22 are recorded between $>30$ and $40 \%$ of time points, 42 between $>20$ and $30 \%, 42$ between $>10$ and $20 \%$ and 70 are recorded at $10 \%$ of time points or less.
Table 7 Time and cost of documentation for case history III.

\begin{tabular}{|lrr|}
\hline Documentation & $\begin{array}{c}\text { Total time } \\
\text { (h:m:s) }\end{array}$ & \multicolumn{1}{c|}{$\begin{array}{c}\text { Total cost } \\
\text { (in } € \text { ) }\end{array}$} \\
\begin{tabular}{|lr} 
Primary diagnosis \\
in a gynecological practice
\end{tabular} & 13.91 \\
\hline $\begin{array}{l}\text { Primary diagnosis and therapy in a breast } \\
\text { center }\end{array}$ & $1: 03: 24$ & 41.14 \\
\hline Primary surgery & $7: 13: 29$ & 266.93 \\
\hline Postoperative planning & $0: 12: 50$ & 9.91 \\
\hline Primary adjuvant chemotherapy & $17: 56: 20$ & 697.42 \\
\hline Radiotherapy & $34: 45: 00$ & 1254.63 \\
\hline Follow-up (follow-up/radiotherapy) & $28: 14: 30$ & 1013.43 \\
\hline Psycho-oncology & $1: 31: 20$ & 73.20 \\
\hline Quality assurance & $3: 26: 36$ & 76.41 \\
\hline Quality management & $0: 50: 50$ & 40.72 \\
\hline Total & $\mathbf{9 5 : 2 8 : 1 9}$ & 3469.70 \\
\hline
\end{tabular}

Table 8 Time and cost of documentation for case history IV.

\begin{tabular}{|c|c|c|}
\hline Documentation & $\begin{array}{l}\text { Total time } \\
\text { (h:m:s) }\end{array}$ & $\begin{array}{l}\text { Total cost } \\
\text { (in } € \text { ) }\end{array}$ \\
\hline $\begin{array}{l}\text { Primary diagnosis } \\
\text { in a gynecological practice }\end{array}$ & $0: 52: 30$ & 45.69 \\
\hline $\begin{array}{l}\text { Primary diagnosis and therapy } \\
\text { in a breast center }\end{array}$ & $0: 47: 26$ & 30.56 \\
\hline Primary surgery & $6: 19: 38$ & 235.53 \\
\hline Postoperative planning & $0: 12: 01$ & 9.19 \\
\hline Follow-up (follow-up/radiotherapy) & $5: 27: 00$ & 225.93 \\
\hline Quality assurance & $3: 19: 41$ & 72.84 \\
\hline Quality management & $0: 50: 50$ & 40.72 \\
\hline Total & $17: 49: 06$ & 660.46 \\
\hline
\end{tabular}




\section{Discussion}

\section{$\nabla$}

Because of the high incidence of breast cancer and the long-term survival of many patients due to continued diagnostic and therapeutic improvements, it is important that the quality of documentation is high. The extent of resources required for documentation is frequently discussed, but real data to underpin this discussion were lacking. As part of the German National Cancer Plan, the decision was taken to focus on the costs, time and resources required for the documentation of patients with breast cancer. Health economy studies to investigate the financial resources required for oncological care, including an examination of potential options to reduce costs, are essential [10]. This study has focused on this issue with the aim of creating transparency and providing detailed information on the real use of resources, which previously could only be estimated; this information can be used in future to optimize the use of resources.

In the single-center stage of this study, the entire course of a patient was mapped in detail from initial diagnosis to the end of follow-up; the focus of this study was on the documentation of patients' data. A total of 484 specific time points were identified when data are documented. However, as many time points recur repeatedly, the total number of documentations can be much higher for individual patients and depend on the time and extent of therapy.

The results of our analysis of time points for documentation, depending on the type of documentation, show that $14.4 \%$ are linked to subsequent follow-up and quality assurance. The percentage relating to quality assurance initially appeared to be rather low. But it must be remembered that this only includes documentations done for the sole purpose of quality assurance. Numerous other documentations, carried out primarily for diagnosis and therapy, are incorporated secondarily in quality assurance. Radiotherapy after breast-conserving surgery is a good example of this. Radiotherapy is documented in detail for every patient undergoing therapy, but radiotherapy is additionally included in quality assurance as one of its quality parameters. To what extent the knowledge that radiotherapy appears secondarily as a parameter of quality assurance affects the extent and thus prolongs the time required for documentation cannot be determined in any detail in this study due to the complexity of the question, but it should be borne in mind when interpreting all the results obtained in this study.

Even though the boundaries between outpatient and in-patient care are extremely fluid nowadays and numerous outpatient services are now provided by hospitals and clinics, documentation time points were assigned to specific sectors. $61.95 \%$ of all documentations are carried out by facilities offering outpatient care. This is a substantial amount, as the majority of documentation is done by hospitals and in-patient facilities. Some of the outpatient documentations are done for quality assurance purposes which are mandatory for hospitals and clinics. But it is also important to remember that numerous outpatient services and the time and cost of documentation they incur are not included in DRGs, so that the financing of documentation done for outpatient services depends on the type of outpatient billing and is often not covered sufficiently.

Another problem is created by the fact that while in-patient facilities carry out the majority of documentation, they often only have limited access to important contents of documentation done in an outpatient setting. Follow-up is a good example of this. Follow-up is generally done by non-hospital based physi- cians, but their findings also have to be documented by certified breast centers, i.e. in-hospital facilities, who receive no compensation for this documentation. It is therefore essential that the links between outpatient and in-patient care providers are not limited to diagnosis and therapy but are expanded to include documentation as well.

Reasons for carrying out a documentation at a specific point in time are interesting. Documentations usually document several different contents (variables). This single-center study examined contents in more detail and identified a number of different reasons for documenting the contents at a specific point in time. Aspects of quality assurance (process quality and outcomes) were identified in $46.8 \%$ of all documentations. This shows that quality assurance goes hand in hand with clinical data collection, but also that quality assurance occurs in almost half of all documentations - at least in university hospitals and certified facilities in the single-center phase.

It is often assumed that documentation is in the hands of only a few persons, particularly in gynecology and senology. This is only partly true. An analysis of who was doing the documentation showed that 21 different medical specialties could be involved in the documentation of a patient with breast cancer, indicating the complexity of the care involved. Gynecology played a particularly important role, carrying out $39.5 \%$ of documentations. However, it should be noted that systemic therapy at the University Breast Center Franconia is carried out by the Department of Gynecology. It could well be that in other certified breast centers this is done by internist oncology, which would, of course, affect the amount of time required by the respective department for documentation. It should also be noted that when analyzing documentation according to the facility doing the documentation, every documentation is only categorized once. Depending on the number of recurrent documentations in each individual case, the demands on medical specialties differ widely, e.g., in a patient treated with radiotherapy, the different treatment sessions increase the number of documentations done by the Department of Radiotherapy, etc. These aspects also need to be taken into account when considering the results of the distribution according to professional group. A total of 20 professional groups can be involved in the documentation of a single breast cancer patient. The majority of the documentation is done by doctors (53.7\% of all documentations). This is especially significant because this group includes the highest paid staff in healthcare.

As the progress of disease for individual breast cancer patients is highly heterogeneous, the system described here is the best structure to calculate the cost and time involved to document every conceivable course. Diagnostics (from diagnosis at mammography screening to diagnosis in an outpatient gynecology practice or in a certified breast center), surgical treatment (breast-conserving therapy versus mastectomy with or without reconstruction; sentinel lymph node biopsy versus axillary dissection, primary surgery versus secondary surgery), systemic therapy (chemotherapy, endocrine therapy, bisphosphonate therapy, antibody therapy) and radiotherapy are all indicated individually, allowing different courses of disease to be calculated. A number of very different case histories were compiled in detail, and the time and cost involved in documenting a patient with each respective case history was calculated. Analysis of the time and cost of documentation highlighted the fact that documentations which have to be repeated multiple times require the most time and therefore money, for example, neoadjuvant systemic therapy, which was calculated as $€ 1009.67$, and radiotherapy 
which was calculated as $€ 1057.76$. These are therapies where it is particularly important that treatment is carried out in accordance with guidelines, making them especially important for quality assurance [11]. If a patient requires less treatment, the cost and time of documentation drops accordingly. Calculating average values is theoretically conceivable but cannot be done in practice, as hundreds of individual diagnostic and therapeutic courses are possible.

The incidence of documented variables is also shown here. In addition to the time and cost of documentation, knowledge of the concrete contents being documented is essential as this can be used to determine where multiple documentations could potentially be avoided. If an online documentation system were available in which all medical specialties and professional groups working in both outpatient and in-patient facilities could enter their data in a uniform format and in which the 58 most common variables were prescribed and only documented once, it would be theoretically possible to depict $60 \%$ of the total documentation and save resources at the same time.

\section{Conclusion \\ $\nabla$}

In Germany the quality of oncological care is already very high. This is also due, in no small measure, to the establishment of certified facilities for oncological care. In addition to the positive effect of improving the quality indicators (QI) which serve as indirect parameters for the quality of outcomes [12,13], certified centers have had a highly significant impact on improving the mortality of breast cancer patients [14] - as demonstrated by the 3 certified centers in Middle Franconia. Similar results have also been reported for a single-center study carried out in the Breast Center of the University Hospital Heidelberg [15]. But care providers are currently burdened with additional costs for which they are not being adequately reimbursed $[16,17]$. The financial and staffing costs required to document breast cancer patients are considerable; in addition to clinical data, considerable time and resources are spent on documentations for quality assurance and quality management required as part of certification, notwithstanding the fact that clinical documentation can also be very detailed, as these data are used secondarily for quality assurance. In the long term, the current high standard of care can only be maintained if there is adequate financial support and if facilities are relieved of some of the costs of documentation. The most important aspect of this expenditure is the financial and staffing cost currently needed for documentation. Measures to reduce the time and cost of documentation are urgently required. A more effective way of collecting and collating data is necessary. Investment in suitable documentation systems with compatible interfaces is necessary. The subsequent impact on healthcare could be considerable:

1. Staffing and financial costs currently used for documentation could be reduced and the resources could be invested in other areas of the healthcare system;

2. This could relieve some of the burden on doctors, many of whom are already working at the limits of their capacity, particularly as there is an increasing shortage of young people entering the profession - even if enough money were available to leave documentation primarily in the hands of doctors, this would not be possible due to the lack of doctors;
3. This could strengthen the position of new professional groups working in healthcare, for example medical documentation assistants specializing in tumor documentation;

4. Quality assurance could be optimized by defining fewer but more relevant quality indicators and ensuring that these data are documented in the same standard format by all professional groups and medical specialties.

Based on the findings of this single-center project, a multi-center survey will be carried out to validate the results of this study and to highlight differences in documentation costs and times in facilities offering different levels of care as well as differences between certified and non-certified facilities.

\section{Acknowledgements \\ $\nabla$}

This study was commissioned by and received financial support from the Federal Ministry of Health.

\section{Conflict of Interest}

$\nabla$

None.

\section{References}

1 Robert Koch-Institut; Gesellschaft der epidemiologischen Krebsregister in Deutschland e.V., Hrsg. Krebs in Deutschland 2009/2010. 9. Ausgabe. Berlin: Robert Koch-Institut; 2013

2 Bundesministerium für Bildung und Forschung. Bevölkerung in Deutschland nach Alter und Geschlecht (Tabelle 0.14). 2012. Online: www.datenportal.bmbf.de; last access: 08.05.2014

3 Lüftner D, Lux MP, Maass $N$ et al. Advances in breast cancer - looking back over the year. Geburtsh Frauenheilk 2012; 72: 1117-1129

4 Beckmann MW. Nationaler Krebsplan des Bundesministeriums für Gesundheit - Strategieplan der Deutschen Krebsgesellschaft. Frauenheilkunde up2date 2009; 5: 323-329

5 Bundesministerium für Gesundheit. Nationaler Krebsplan. Online: http://www.bmg.bund.de/cln_169/nn_1168248/SharedDocs/ Standardartikel/DE/AZ/N/Glossarbegriff-Nationaler-Krebsplan.html\# doc1632822bodyText14; last access: Februar 2010

6 Kowalski C, Wesselmann S, Kreienberg R et al. The patients' view on accrediated breast cancer centers: Strengths and potential for improvement. Geburtsh Frauenheilk 2012; 72: 137-143

7 Querschnitts-AG Dokumentation. Datensparsame einheitliche Tumordokumentation - eine Kernforderung des Nationalen Krebsplans. Endfassung 10.10.2011. Online: www.tumorzentren.de/NationalerKrebsplan.html; last access: 07.08.2014

8 Tarifgemeinschaft deutscher Länder, Hrsg. Tarifvertrag für Ärztinnen und Ärzte an Universitätskliniken (TV-Ärzte). vom 30. Oktober 2006 in der Fassung des Änderungstarifvertrages Nr. 1 vom 27. August 2009. Online: http://www.uni-erlangen.de/einrichtungen/personalabteilung/; last access: 17.04.2011

9 Bundesärztekammer, Hrsg. Gehaltstarifvertrag für Medizinische Fachangestellte. In: Deutsches Ärzteblatt (106/24). Online: http://www. aerzteblatt.de/download/files/2009/06/down137850.pdf; last access: 24.11.2011

10 Kolberg H-C, Lüftner D, Lux MP et al. Breast cancer 2012 - New aspects. Geburtsh Frauenheilk 2012; 72: 602-615

11 Kreienberg R, Albert U-S, Follmann $M$ et al. Interdisciplinary GoR level III guidelines for the diagnosis, therapy and follow-up care of breast cancer. Geburtsh Frauenheilk 2013; 73: 556-583

12 Brucker SY, Schumacher C, Sohn C et al. Benchmarking the quality of breast cancer care in a nationwide voluntary system: the first five-year results (2003-2007) from Germany as a proof of concept. BMC Cancer 2008; 8: 358

13 Brucker SY, Bamberg M, Jonat W et al. Certification of breast centres in Germany: proof of concept for a prototypical example of quality assurance in multidisciplinary cancer care. BMC Cancer 2009; 9: 228 
14 Beckmann MW, Brucker C, Hanf V et al. Quality assured health care in certified breast centers and improvement of prognosis of breast cancer patients. Onkologie 2011; 34: 362-367

15 Heil J, Gondos A, Rauch G et al. Outcome analysis of patients with primary breast cancer initially treated at a certified academic breast unit. Breast 2012; 21: 303-308
16 Beckmann MW, Bani MR, Loehberg CR et al. Are certified breast centers cost-effective? Breast Care 2009; 4: 245-250

17 Lux MP, Hildebrandt T, Beyer-Finkler E et al. Relevance of health economics in breast cancer treatment - the view of certified breast centres and their patients. Breast Care 2013, 8: 15-21 